Pacific Journal of Mathematics

FIXED POINTS OF LOCALLY CONTRACTIVE AND 


\title{
FIXED POINTS OF LOCALLY CONTRACTIVE AND NONEXPANSIVE SET-VALUED MAPPINGS
}

\author{
Peter K. F. Kuhfittig
}

Let $(M, d)$ be a complete metric space and $S(M)$ the set of all nonempty bounded closed subsets of $M$. A set-valued mapping $f: M \rightarrow S(M)$ will be called (uniformly) locally contractive if there exist $\varepsilon$ and $\lambda(\varepsilon>0,0<\lambda<1)$ such that $D(f(x), f(y)) \leqq \lambda d(x, y)$ whenever $d(x, y)<\varepsilon$ and where $D(f(x)$, $f(y)$ ) is the distance between $f(x)$ and $f(y)$ in the Hausdorff metric induced by $d$ on $S(M)$. It is shown in the first theorem that if $M$ is "well-chained," then $f$ has a fixed point is, that is, a point $x \in M$ such that $x \in f(x)$. This fact, in turn, yields a fixed-point theorem for locally nonexpansive set-valued mappings on a compact star-shaped subset of a Banach space. Both theorems are extensions of earlier results.

1. Locally contractive set-valued mappings. Following Assad and Kirk [1] we shall define $D$ as follows: if $r>0$ and $Y \in S(M)$, let

$$
Z(r, Y)=\{x \in M: \operatorname{dist}(x, Y)<r\} .
$$

Then for $A, B \in S(M)$ we define

$$
D(A, B)=\inf \{r: A \subset Z(r, B) \text { and } B \subset Z(r, A)\} .
$$

Also noted in [1] are two lemmas:

Lemma 1. If $A, B \in S(M)$ and $x \in A$, then for each positive number $\alpha$ there exists $y \in B$ such that

$$
d(x, y) \leqq D(A, B)+\alpha .
$$

LEMMA 2. Let $\left\{X_{n}\right\}$ be a sequence of sets in $S(M)$, and assume that $\lim _{n \rightarrow \infty} D\left(X_{n}, X_{0}\right)=0\left(X_{0} \in S(M)\right)$. Then if $x_{n} \in X_{n}(n=1,2, \cdots)$ and $\lim _{n \rightarrow \infty} x_{n}=x_{0}$, it follows that $x_{0} \in X_{0}$.

Finally, suppose $M$ is well-chained in the sense that for every $\varepsilon>0$ and $x, y \in M$ there exists an $\varepsilon$-chain, that is, a finite set of points

$$
x=y_{0}, y_{1}, \cdots, y_{n}=z
$$

( $n$ may depend on both $x$ and $z$ ) such that $d\left(y_{i}, y_{i+1}\right)<\varepsilon(i=$ $0,1, \cdots, n-1)$. 
Theorem 1. Suppose $(M, d)$ is a complete well-chained metric space and $S(M)$ the set of all nonempty bounded closed subsets of $M$. If $f: M \rightarrow S(M)$ is locally contractive, then $f$ has a fixed point. Then

Proof. Assume that $\varepsilon<1$ and let $x_{0}, y_{0} \in M$ such that $d\left(x_{0}, y_{0}\right)<\varepsilon$.

$$
D\left(f\left(x_{0}\right), f\left(y_{0}\right)\right) \leqq \lambda d\left(x_{0}, y_{0}\right) .
$$

Now choose a positive number $\eta<\varepsilon-\lambda \varepsilon<1$. Let $x_{1}$ be any element in $f\left(x_{0}\right)$; then there exists by Lemma 1 an element $y_{1} \in f\left(y_{0}\right)$ such that

$$
d\left(x_{1}, y_{1}\right) \leqq D\left(f\left(x_{0}\right), f\left(y_{0}\right)\right)+\eta
$$

Hence

$$
d\left(x_{1}, y_{1}\right)<\lambda \varepsilon+\eta<\lambda \varepsilon+\varepsilon-\lambda \varepsilon=\varepsilon .
$$

Next, let $x_{2} \in f\left(x_{1}\right)$; then there exists $y_{2} \in f\left(y_{1}\right)$ such that

$$
\begin{aligned}
d\left(x_{2}, y_{2}\right) & \leqq D\left(f\left(x_{1}\right), f\left(y_{1}\right)\right)+\eta^{2} \\
& \leqq \lambda d\left(x_{1}, y_{1}\right)+\eta^{2} .
\end{aligned}
$$

In general, for $n>0$

$$
d\left(x_{n}, y_{n}\right) \leqq D\left(f\left(x_{n-1}\right), f\left(y_{n-1}\right)\right)+\eta^{n},
$$

and we can show by induction that

$$
d\left(x_{n}, y_{n}\right)<\lambda^{n} \varepsilon+\lambda^{n-1} \eta+\lambda^{n-2} \eta^{2}+\cdots+\eta^{n} .
$$

Indeed,

$$
\begin{aligned}
\lambda^{n} \varepsilon & +\lambda^{n-1} \eta+\lambda^{n-2} \eta^{2}+\cdots+\eta^{n} \\
& <\lambda^{n} \varepsilon+\lambda^{n-1}(\varepsilon-\lambda \varepsilon)+\lambda^{n-2}(\varepsilon-\lambda \varepsilon)^{2}+\cdots+(\varepsilon-\lambda \varepsilon)^{n} \\
& \leqq \lambda^{n} \varepsilon+\lambda^{n-1}(\varepsilon-\lambda \varepsilon)+\lambda^{n-2}(\varepsilon-\lambda \varepsilon)+\cdots+(\varepsilon-\lambda \varepsilon) \\
& =\lambda^{n} \varepsilon+\left(\lambda^{n-1} \varepsilon-\lambda^{n} \varepsilon\right)+\left(\lambda^{n-2} \varepsilon-\lambda^{n-1} \varepsilon\right)+\cdots+(\varepsilon-\lambda \varepsilon) \\
& =\varepsilon .
\end{aligned}
$$

So if (1) is valid for $n=N>0$, let $x_{N+1} \in f\left(x_{N}\right)$; then there exists $y_{N+1} \in f\left(y_{N}\right)$ such that

$$
\begin{aligned}
d\left(x_{N+1}, y_{N+1}\right) & \leqq D\left(f\left(y_{N}\right), f\left(y_{N}\right)\right)+\eta^{N+1} \leqq \lambda d\left(x_{N}, y_{N}\right)+\eta^{N+1} \\
& <\lambda\left(\lambda^{N} \varepsilon+\lambda^{N-1} \eta+\lambda^{N-2} \eta^{2}+\cdots+\eta^{N}\right)+\eta^{N+1} \\
& =\lambda^{N+1} \varepsilon+\lambda^{N} \eta+\lambda^{N-1} \eta^{2}+\cdots+\lambda \eta^{N}+\eta^{N+1} .
\end{aligned}
$$

Using this information we now construct a sequence in $M$ as follows: let $y_{0,0}$ be an arbitrary element in $M$ and let $y_{1,0} \in f\left(y_{0,0}\right)$. 
Consider the $\varepsilon$-chain

$$
y_{0,0}, y_{0,1}, \cdots, y_{0, n}=y_{1,0} \in f\left(y_{0,0}\right) \text {, }
$$

so that $d\left(y_{0, i}, y_{0, i+1}\right)<\varepsilon(i=0,1, \cdots, n-1)$. Since $y_{1,0} \in f\left(y_{0,0}\right)$, we may choose $y_{1,1} \in f\left(y_{0,1}\right)$ such that

$$
d\left(y_{1,0}, y_{1,1}\right) \leqq D\left(f\left(y_{0,0}\right), f\left(y_{0,1}\right)\right)+\eta \text {. }
$$

Similarly, since $y_{1,1} \in f\left(y_{0,1}\right)$, choose $y_{1,2} \in f\left(y_{0,2}\right)$ such that

$$
d\left(y_{1,1}, y_{1,2}\right) \leqq D\left(f\left(y_{0,1}\right), f\left(y_{0,2}\right)\right)+\eta \text {. }
$$

Continuing along the $\varepsilon$-chain, since $y_{1, n-1} \in f\left(y_{0, n-1}\right)$, there exists $y_{1, n}=$ $y_{2,0} \in f\left(y_{0, n}\right)$ (i.e., $\left.y_{2,0} \in f\left(y_{1,0}\right)\right)$ such that

$$
d\left(y_{1, n-1}, y_{1, n}\right) \leqq D\left(f\left(y_{0, n-1}\right), f\left(y_{0, n}\right)\right)+\eta \text {. }
$$

Consequently,

$$
d\left(y_{1,0}, y_{2,0}\right)=d\left(y_{1,0}, y_{1, n}\right) \leqq \sum_{i=0}^{n-1} d\left(y_{1, i}, y_{1, i+1}\right)<n(\lambda \varepsilon+\eta)
$$

Next, referring to (2), since $y_{2,0} \in f\left(y_{1,0}\right)$, there exists $y_{2,1} \in f\left(y_{1,1}\right)$ for which

$$
d\left(y_{2,0}, y_{2,1}\right) \leqq D\left(f\left(y_{1,0}\right), f\left(y_{1,1}\right)\right)+\eta^{2},
$$

and for $y_{2, n-1} \in f\left(y_{1, n-1}\right)$, we have $y_{2, n}=y_{3,0} \in f\left(y_{1, n}\right)$ (i.e., $y_{3,0} \in f\left(y_{2,0}\right)$ ) such that

$$
d\left(y_{2, n-1}, y_{2, n}\right) \leqq D\left(f\left(y_{1, n-1}\right), f\left(y_{1, n}\right)\right)+\eta^{2} .
$$

Proceeding in this manner, and making use of (1), we get (for $m>0$ )

$$
d\left(y_{m, l}, y_{m, l+1}\right)<\lambda^{m} \varepsilon+\lambda^{m-1} \eta+\lambda^{m-2} \eta^{2}+\cdots+\eta^{m}
$$

$(l=0,1, \cdots, n-1)$. Now let $z_{m}=y_{m, 0}$, so that $z_{m} \in f\left(z_{m-1}\right), m=$ $1,2, \cdots$, and $z_{m+1}=y_{m+1,0}=y_{m, n}$. Then

$$
\begin{aligned}
d\left(z_{m}, z_{m+1}\right) & \leqq \sum_{l=0}^{n-1} d\left(y_{m, l}, y_{m, l+1}\right) \\
& <n\left(\lambda^{m} \varepsilon+\lambda^{m-1} \eta+\lambda^{m-2} \eta^{2}+\cdots+\eta^{m}\right) .
\end{aligned}
$$

To show that $\left\{z_{m}\right\}$ is a Cauchy sequence, let $\beta=\max (\lambda, \eta)$. Then

$$
d\left(z_{m}, z_{m+1}\right)<n(m+1) \beta^{m},
$$

and for $0<i<j$ 


$$
\begin{aligned}
d\left(z_{i}, z_{j}\right) & \leqq \sum_{k=i}^{j-1} d\left(z_{k}, z_{k+1}\right) \\
& <n \sum_{k=i}^{j-1}(k+1) \beta^{k} \\
& \leqq n \sum_{k=i}^{\infty}(k+1) \beta^{k}
\end{aligned}
$$

It is easily checked that $d\left(z_{i}, z_{j}\right) \rightarrow 0$ as $i \rightarrow \infty$, implying that $\left\{z_{m}\right\}$ is a Cauchy sequence, which converges to some $z \in M$ by the completeness of $M$.

Finally, since $z_{m} \in f\left(z_{m-1}\right)$ and $z_{m} \rightarrow z, f\left(z_{m-1}\right) \rightarrow f(z)$ and, by Lemma $2, z \in f(z)$.

REMARK 1. Nadler [4] proved a similar theorem by a different method under the additional assumption that each $f(x)$ is compact.

2. Locally nonexpansive set-valued mappings. Let $X$ be a Banach space and $C$ a subset of $X$. A mapping $T: C \rightarrow S(C)$ will be called locally nonexpansive if there exists $\varepsilon>0$ such that

$$
D(T x, T y) \leqq\|x-y\|
$$

whenever $\|x-y\|<\varepsilon$ and where $D$ is again the distance in the Hausdorff metric induced by $d$ on $S(M)$ (as usual, $d(x, y)=\|x-y\|$ for all $x, y \in X)$.

THEOREM 2. Let $X$ be a Banach space and $C$ a compact starshaped subset of $X$. If $T: C \rightarrow S(C)$ is locally nonexpansive, then there exists a point $x \in C$ such that $x \in T x$.

Proof. Let $c$ be the star-center of $C$ and let $\left\{k_{n}\right\}$ be an increasing sequence of real numbers converging to 1 . Define $U_{n}: C \rightarrow S(C)$ by

$$
U_{n} x=\left(1-k_{n}\right) c+k_{n} T x,
$$

where $k_{n} T x=\left\{k_{n} y: y \in T x\right\}$. Let $z, y \in C$ such that $\|z-y\|<\varepsilon$. Then $D(T z, T y) \leqq\|z-y\|$. Now for any two elements $z^{\prime} \in T z$ and $y^{\prime} \in T y$

$$
\left\|\left(1-k_{n}\right) c+k_{n} z^{\prime}-\left(1-k_{n}\right) c-k_{n} y^{\prime}\right\|=k_{n}\left\|z^{\prime}-y^{\prime}\right\| .
$$

Hence

$$
D\left(U_{n} z, U_{n} y\right) \leqq k_{n}\|z-y\| .
$$

Consequently, $U_{n}$ has a fixed point $x_{n} \in C$ by Theorem 1 . Since $C$ is 
compact, there exists a subsequence $\left\{x_{n_{i}}\right\}$ of $\left\{x_{n}\right\}$ converging to some $x \in C$, and because $T$ is continuous,

$$
T x_{n_{i}} \longrightarrow T x \text {. }
$$

Now

$$
\begin{aligned}
& \operatorname{dist}\left(x_{n_{i}}, T x_{n_{i}}\right) \leqq D\left(U_{n_{i}} x_{n_{i}}, T x_{n_{i}}\right) \\
& \quad=D\left(\left(1-k_{n_{i}}\right) c+k_{n_{i}} T x_{n_{i}}, T x_{n_{i}}\right) \longrightarrow D(T x, T x) \text { as } i \longrightarrow \infty .
\end{aligned}
$$

Thus

$$
\operatorname{dist}(x, T x)=0,
$$

which implies that $x \in T x, T x$ being closed.

Theorem 2 and its point-to-point analogue generalize an earlier theorem due to Dotson [2]:

CoRollary. A nonexpansive self-mapping of a compact starshaped subset of a Banach space has a fixed point.

REMARK 2. Edelstein [3] has shown that a locally contractive (nonexpansive) point-to-point mapping need not be globally contractive (nonexpansive). On convex sets, however, a locally nonexpansive mapping is nonexpansive.

\section{REFERENCES}

1. N.A. Assad and W.A. Kirk, Fixed point theorems for set-valued mappings of contractive type, Pacific J. Math., 43 (1972), 553-562.

2. W. G. Dotson, Jr., Fixed point theorems for nonexpansive mappings on star-shaped subsets of Banach spaces, J. London Math. Soc., (2) 4 (1972), 408-410.

3. M. Edelstein, An extension of Banach's contraction principle, Proc. Amer. Math. Soc., 12 (1961), 7-10.

4. S. B. Nadler, Jr., Multi-valued contraction mappings, Pacific J. Math., 30 (1969), 475-488.

Received August 12, 1975.

Milwaukee School of Engineering 



\section{PACIFIC JOURNAL OF MATHEMATICS}

\section{EDITORS}

RICHARD ARENS (Managing Editor)

University of California

Los Angeles, California 90024

\section{R. A. Beaumont}

University of Washington

Seattle, Washington 98105
J. DugundjI

Department of Mathematics

University of Southern California

Los Angeles, California 90007

D. Gilbarg and J. Milgram

Stanford University

Stanford, California 94305

\section{ASSOCIATE EDITORS}
E. F. BECKENBACH
B. H. NeumanN
F. WOLF
K. YosHIDA

\section{SUPPORTING INSTITUTIONS}

\author{
UNIVERSITY OF BRITISH COLUMBIA \\ CALIFORNIA INSTITUTE OF TECHNOLOGY \\ UNIVERSITY OF CALIFORNIA \\ MONTANA STATE UNIVERSITY \\ UNIVERSITY OF NEVADA \\ NEW MEXICO STATE UNIVERSITY \\ OREGON STATE UNIVERSITY \\ UNIVERSITY OF OREGON \\ OSAKA UNIVERSITY
}

\author{
UNIVERSITY OF SOUTHERN CALIFORNIA \\ STANFORD UNIVERSITY \\ UNIVERSITY OF HAWAII \\ UNIVERSITY OF TOKYO \\ UNIVERSITY OF UTAH \\ WASHINGTON STATE UNIVERSITY \\ UNIVERSITY OF WASHINGTON \\ AMERICAN MATHEMATICAL SOCIETY
}

The Supporting Institutions listed above contribute to the cost of publication of this Journal, but they are not owners or publishers and have no responsibility for its content or policies.

Mathematical papers intended for publication in the Pacific Journal of Mathematics should be in typed form or offset-reproduced, (not dittoed), double spaced with large margins. Please do not use built up fractions in the text of your manuscript. You may however, use them in the displayed equations. Underline Greek letters in red, German in green, and script in blue. The first paragraph or two must be capable of being used separately as a synopsis of the entire paper. Items of the bibliography should not be cited there unless absolutely necessary, in which case they must be identified by author and Journal, rather than by item number. Manuscripts, in triplicate, may be sent to any one of the editors. Please classify according to the scheme of Math. Reviews, Index to Vol. 39. All other communications should be addressed to the managing editor, or Elaine Barth, University of California, Los Angeles, California, 90024.

The Pacific Journal of Mathematics expects the author's institution to pay page charges, and reserves the right to delay publication for nonpayment of charges in case of financial emergency.

100 reprints are provided free for each article, only if page charges have been substantially paid. Additional copies may be obtained at cost in multiples of 50 .

The Pacific Journal of Mathematics is issued monthly as of January 1966. Regular subscription rate: $\$ 72.00$ a year (6 Vols., 12 issues). Special rate: $\$ 36.00$ a year to individual members of supporting institutions.

Subscriptions, orders for back numbers, and changes of address should be sent to Pacific Journal of Mathematics, 103 Highland Boulevard, Berkeley, California, 94708.

PUBLISHED BY PACIFIC JOURNAL OF MATHEMATICS, A NON-PROFIT CORPORATION

Printed at Kokusai Bunken Insatsusha (International Academic Printing Co., Ltd.), 8-8, 3-chome, Takadanobaba, Shinjuku-ku, Tokyo 160, Japan. 


\section{Pacific Journal of Mathematics \\ Vol. 65, No. $2 \quad$ October, 1976}

Andrew Adler, Weak homomorphisms and invariants: an example .......... 293

Howard Anton and William J. Pervin, Separation axioms and metric-like

functions ............................................. 299

Ron C. Blei, Sidon partitions and p-Sidon sets .................... 307

T. J. Cheatham and J. R. Smith, Regular and semisimple modules ........... 315

Charles Edward Cleaver, Packing spheres in Orlicz spaces .............. 325

Le Baron O. Ferguson and Michael D. Rusk, Korovkin sets for an operator on a

space of continuous functions ............................. 337

Rudolf Fritsch, An approximation theorem for maps into Kan fibrations ....... 347

David Sexton Gilliam, Geometry and the Radon-Nikodym theorem in strict

Mackey convergence spaces .................................

William Hery, Maximal ideals in algebras of topological algebra valued

functions ...................................... 365

Alan Hopenwasser, The radical of a reflexive operator algebra ........... 375

Bruno Kramm, A characterization of Riemann algebras................. 393

Peter K. F. Kuhfittig, Fixed points of locally contractive and nonexpansive

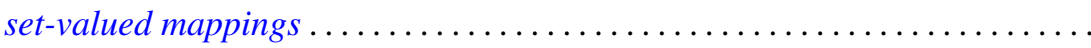

Stephen Allan McGrath, On almost everywhere convergence of Abel means of

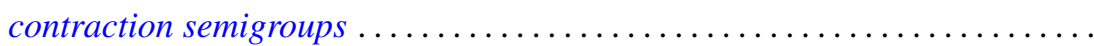

Edward Peter Merkes and Marion Wetzel, A geometric characterization of

indeterminate moment sequences............................ 409

John C. Morgan, II, The absolute Baire property ................... 421

Eli Aaron Passow and John A. Roulier, Negative theorems on generalized convex approximation .................................... 437

Louis Jackson Ratliff, Jr., A theorem on prime divisors of zero and characterizations of unmixed local domains ..............

Ellen Elizabeth Reed, A class of $T_{1}$-compactifications................... 471

Maxwell Alexander Rosenlicht, On Liouville's theory of elementary

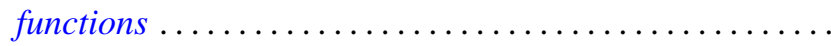

Arthur Argyle Sagle, Power-associative algebras and Riemannian

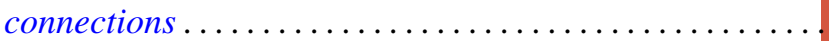

Chester Cornelius Seabury, On extending regular holomorphic maps from Stein manifolds...

Elias Sai Wan Shiu, Commutators and numerical ranges of powers of operators ...................................

Donald Mark Topkis, The structure of sublattices of the product of $n$ lattices ... 525

John Bason Wagoner, Delooping the continuous $K$-theory of a valuation

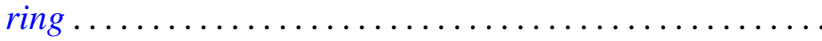

Ronson Joseph Warne, Standard regular semigroups...........

Anthony William Wickstead, The centraliser of $E \otimes_{\lambda} F \ldots$. 